\title{
Model-based Systems Engineering and Through-life Information Management in Complex Construction
}

- Cite this paper as:

Chen, Y. and Jupp, J., 2018, July. Model-Based Systems Engineering and Through-Life Information Management in Complex Construction. In IFIP International Conference on Product Lifecycle Management (pp. 80-92). Springer, Cham.

\section{- Additional Information:}

This is an Accepted Manuscript of a conference paper published by IFTP Advances in Information and Communication Technology on July 2018. 


\title{
Model-based Systems Engineering and Through-life Information Management in Complex Construction
}

\author{
Yu Chen* and Julie Jupp \\ School of Built Environment, University of Technology Sydney \\ Sydney, Australia \\ Yu. Chenduts. edu. au
}

\begin{abstract}
With increasing maturity in model-based design and construction, a concomitant increase in the need for system-based methodologies and toolsets to support systems integration, requirements management, verification and validation and configuration management is evident if model-based information is to serve the operations of complex buildings and civil infrastructure projects. There is much to learn from best practices reported in complex discrete manufacturing. In particular, closed-loop product lifecycle management (PLM), systems engineering (SE) and model-based systems engineering (MBSE) are key to systems approaches to digital complex construction delivery and the reuse of model-based information for operations and maintenance $(\mathrm{O} \& \mathrm{M})$. The paper reviews related research and investigates the role of the $\mathrm{V}$-model in the development process, discussing its significance to structuring a through-life approach to information management. A discussion of Erasmus' PLM aligned V-model is presented, and missing links in current BIM-enabled environments are identified relative to requirements engineering, verification and validation, and configuration management. The paper closes with a discussion of the gaps in supporting model-based tool ecologies and lack of a central structuring infrastructure, as well as the deficiencies in current process and data standards. Closing with the identification of a future research agenda.
\end{abstract}

Keywords: Building information modelling, Through-life information management, Systems engineering, Model-based systems engineering.

\section{Introduction}

Within the lifecycle of a building asset, different actor-groups are involved in generating and sharing data and information throughout the design, construction, and operations and maintenance $(\mathrm{O} \& \mathrm{M})$ phases [1]. The fragmented nature of both the construction and facilities management (FM) industries leads to the inefficient exchange and low reuse of asset information [1,2]. During the past decade more effective utilization of product and product-related information has improved in the development of new complex buildings and infrastructure [3]. Building Information Modelling (BIM) is widely regarded as a key enabler of this trend, and together with the increased use of sensors and the internet of things (IoT), the foundation of the fourth industrial revolution, or Industry 4.0 are being laid [3]. BIM is defined as "a new approach to design, construction, and FM, in which a 
digital representation of the asset process is used to facilitate the exchange and interoperability of information in digital format" [4]. The implementation of BIM in design and construction phases brings with it benefits regarding performance-based simulation and analysis, as well as greater cost and schedule control [5]. Yet these benefits are marginal in light of the potential gains to the O\&M of a facility's assets [6]. The realization of a through-life approach to product data and information management faces a variety of persistent barriers. Issues relate to the highly fragmented nature of the construction supply chain, traditional procurement methods, and lack of process standardization [9]. These and other barriers related to technology infrastructures $[10,25]$ prohibit the integration and flow of model-based product information [7]. The knock-on effects of these barriers on the management of vast amounts of data and information generated are significant and prohibits an integrated systems approach to development processes [8].

To capitalize more fully on the potential of BIM to support the integrated flow of digital information and process activities, it is necessary to define a structuring concept linking BIM models, BIM uses, related information flows in the project together, with workflows that commence at requirements elicitation and analysis and include defined verification and validation $(\mathrm{V} \& \mathrm{~V})$ activities capable of supporting both functional product and information quality assurance together with linked with user profile information $[9,10]$. Previous researchers have identified how the application of systems engineering (SE) activities in construction can structure the flow of data and information as well as process activities $[11,12]$. SE is a multidiscipline approach that (i) supports the realization of complex systems integration, (ii) using requirements engineering methods increases the project team's ability to deliver high quality products, and (iii) services a variety of different business processes across the organization [13]. Key to SE is the emphasis on requirements traceability through-life to achieve the alignment of components, units, subsystems, and system [14]. However, whilst SE provides a robust set of methods and processes (e.g., information requirements management [3], configuration management [15, $16]$ and change management $[17,18])$, gaps remain in how these methods translate to the complex nature of construction projects, where challenges persist in the implementation of BIM surrounding the way data is structured, verified, validated, reused and managed over the lifecycle of the asset $[1,3,19,20]$. Recent initiatives to develop BIM Standards (e.g., PAS 1192 and ISO/DIS 19650) have sought to address such issues. However, an understanding of how SE methods and processes can be used to implement systems-based collaborative methodologies is currently lacking.

Against this backcloth, this paper presents a review and discussion of related literature surrounding BIM and through-life information management. The paper introduces the widely used V-model, popularized in the SE research in support of development processes in complex discrete manufacturing. The paper discusses BIM tool ecologies and standards in light of V-model objectives. Focusing on requirements management, verification and validation and configurations management activities, gaps are identified in construction practice. The paper ends with a discussion of the role of SE methods in support of in complex building and infrastructure projects. 


\section{Background}

With the increasing uptake of model-based design and construction technologies during project delivery, opportunities for reusing information throughout the life of the asset have arisen. Accordingly, technologies supporting the required backbone infrastructure, data structuring, cloud provisioning services, and enterprise architectures have also emerged. Much effort has also been made to support interoperability, where data standards have sought to support data exchange across various AEC disciplines. Remaining challenges for the successful delivery of both the physical and digital asset surround the use of various data standards and immaturity in the use of BIM process standards that support the use of BIM in the delivery of 3D 'as-builts' and associated data for O\&M. Whilst best practices in the specification of information requirements during project delivery to support BIM-enabled O\&M/ FM, the implementation requirements of throughlife information management relative to key verification and validation processes, and configurations management remain relatively unknown. A significant issue remaining in the fragmented supply chains of construction and FM industries is the difficulty in determining "what data and context are required for each phase of the product lifecycle" [21].

Over the last three decades, the complex, discrete manufacturing industries have made significant progress in productivity increases and management efficiencies. This is in large part due to a more seamless integration of systems enabled by SE methods and the technology infrastructure that Product Lifecycle Management (PLM) platforms provide $[9,21,22]$. Similar improvements, however, have not been achieved in the construction and FM industries [9]. Given the increasingly cyber-physical nature of these industries in the last decade, SE and recent approaches to model-based systems engineering (MBSE) have the potential to inform new approaches to BIM-enabled systems integration and through-life information management $[9,11,14]$.

In the field of information processing, researchers investigating lifecycle approaches to BIM have explored the relevance of PLM. Whilst PLM is a business-oriented solution, at its core PLM is a software-enabled strategy streamlines the flow of information about the product and related processes throughout the product's lifecycle. As such, the right information, in the right context, at the right time can be made available [23]. By providing the backbone technology infrastructure to improve processes to conceptualize, design, develop and manage products, PLM implementations drive higher levels of productivity and product profitability [29]. Jupp [9] presents a typology for comparing PLM and BIM in a comprehensive literature review, undertaking comparative analysis between aerospace and construction. The study highlights that the similarities between PLM and BIM trajectories stem from a few common but key characteristics surrounding data requirements, object-oriented approaches to modelling and visualization, project level data sharing, and organization of teams around digital deliverables [9]. Jupp and Nepal [24] explore how BIM and PLM have impacted the professional practices in construction and manufacturing industries. They concluded that the level of BIM maturity across the construction industry is improving; increasing the possibility to reach a "common endpoint with manufacturing industries". Boton et al. [10, 25] present a comparison between the PLM and BIM approaches from the standpoint of the Product Structure (PS) and Bill of 
Material (BOM), highlighting significant differences in approaches to 3D modelling and systems decomposition, data structures and workflow automation [25].

Other notable research works include studies on the adoption of SE approaches in construction $[1,14,26,27]$. Whyte [14] provides a comprehensive review of system integration research in the delivery and operation of infrastructure projects and suggests future directions for research on systems integration within the civil infrastructure. Whyte highlights the potential of combining "data-sets and model-based systems engineering, BIM and performance-based models" and using "new forms of data analytics to reveal new patterns" [14]. A chief concern raised by the translation of SE into a built environment context is the reliance on a single source of data and the potential for errors and significant failures in the absence of robust processes for information verification and validation throughout the project [14]. Hoeber \& Alsem [1] present a way of working that utilizes open-standard BIM, SE ontologies, object libraries and an Information Delivery Manual to support information management throughout the life of infrastructures assets. Mata et al. [26] develop a 'Systems of Systems' model using SE concepts and Systems Modeling Language (SysML) to evaluate the sustainability performance of infrastructure projects. Notably, De Graaf et al. [27] assessed the level of SE applications in six construction projects of the Dutch Water Board based on the SE process model developed by the U.S. Department of Defense (DoD).

This growing body of literature signals the case for understanding SE methods and PLM functionalities relative to the unique context and requirements of designing, delivering and O\&M of facility assets.

\section{Model-based Systems Engineering and the PLM V-Model}

One of the most accepted definitions of SE is that proposed by INCOSE: "SE is an interdisciplinary approach and means to enable the realization of successful systems. It focuses on defining customer needs and required functionality early in the development cycle, documenting requirement, and then proceeding with design synthesis and system validation while considering the complete problem." [13]. Model-based systems engineering (MBSE), is an approach that is founded in SE, and is aimed at the use of models (instead of documents) to support system requirements, design, analysis, verification and validation of the system being developed [28]. The "V" model, one of the most widely used development process models in SE that takes a lifecycle approach, describing the through-life requirements management, and continuous verification and validation processes [13]. In typical V-model representations, traceability is ensured from both "horizontal" and "vertical" verification and validation linkages [29]. During system decomposition and definition, requirements, functions, and objects (R/F/O) are verified with higher-level R/F/O before then being validated against client expectations, which enable the "vertical" traceability [30]. The components of a system are then integrated and recomposed into the product. System components are therefore verified with corresponding $\mathrm{R} / \mathrm{F} / \mathrm{O}$ at each level with ongoing validation, which enable the "horizontal" traceability $[30,31]$. In this way, $V \& V$ are not treated as separate phases but are integrated activities executed continuously throughout the MBSE process [30]. 
Erasmus et al. [32] have united the V-model development processes and PLM's backbone infrastructure to produce a framework that aligns objectives and capabilities to support model-based delivery processes. Fig. 1 shows this alignment between PLM and a MBSE V-model. The model describes requirements [R], functions [F], logical solution elements [L], and physical elements [P]. Using a PLM platform, three information management capabilities can be harnessed to enabled MBSE, including the integration: (i) of product information across the entire lifecycle and the associated information, (ii) for improved collaboration between practitioners from different disciplines and business functions, and (iii) of people, data, processes and business systems to provide a product information methodology for the company and its extended enterprise [32].

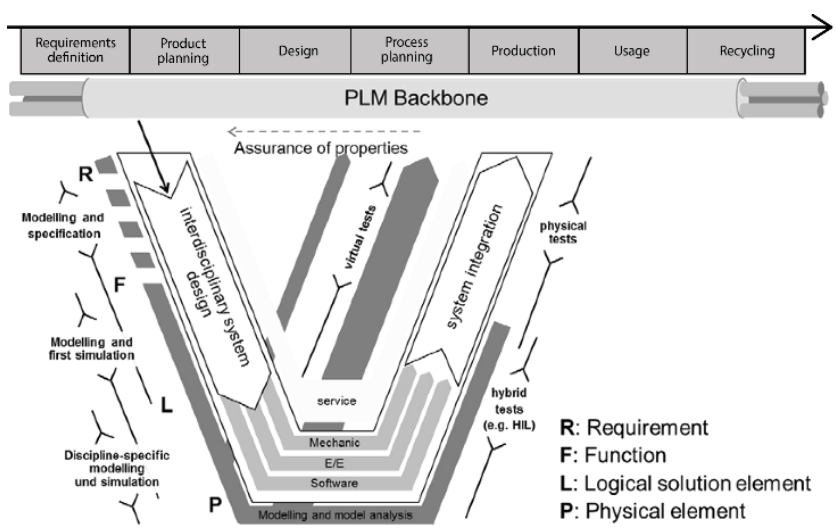

Fig. 1. PLM aligned V-model to enable model-based systems engineering [33]

In Erasmus' PLM V-model, time and system maturity proceed from the left "wing" (topdown) to the right "wing" (bottom-up) [13]. Top-down processes reflect the definition and decomposition of the system into sub-systems and components; while the bottom-up approach enables the integration and verification from system components to the system level [31]. In MBSE approaches, the "V" reflects the definition of model-based V\&V plans during the top-down requirements developments process. In a BIM-enabled environment, the development of information management methodologies relies on similar approaches, for example as reflected in EIR definitions in PAS 1192.3-2014. However, Erasmus' combined PLM V-model highlights further deficiencies in the application of BIM, where as a model-based development process it should be supported by similar mechanisms that can facilitate the relationship between the various participants in the supply chain and their model-based deliverables, by enabling the exchange of the information that describes the product, its configuration, its intended use, and how it will be maintained. 


\section{New Complex Construction and Information Management}

This section introduces a conceptual framework that attempts to describe the different approaches to model-based design, construction and operations. The framework illustrated in Fig. 2 provides a means of identifying and structuring the problem of implementing a through-life approach to information management in a construction context so as to highlight the gaps to model-based requirements management, verification and validation, and configuration management processes and infrastructures.

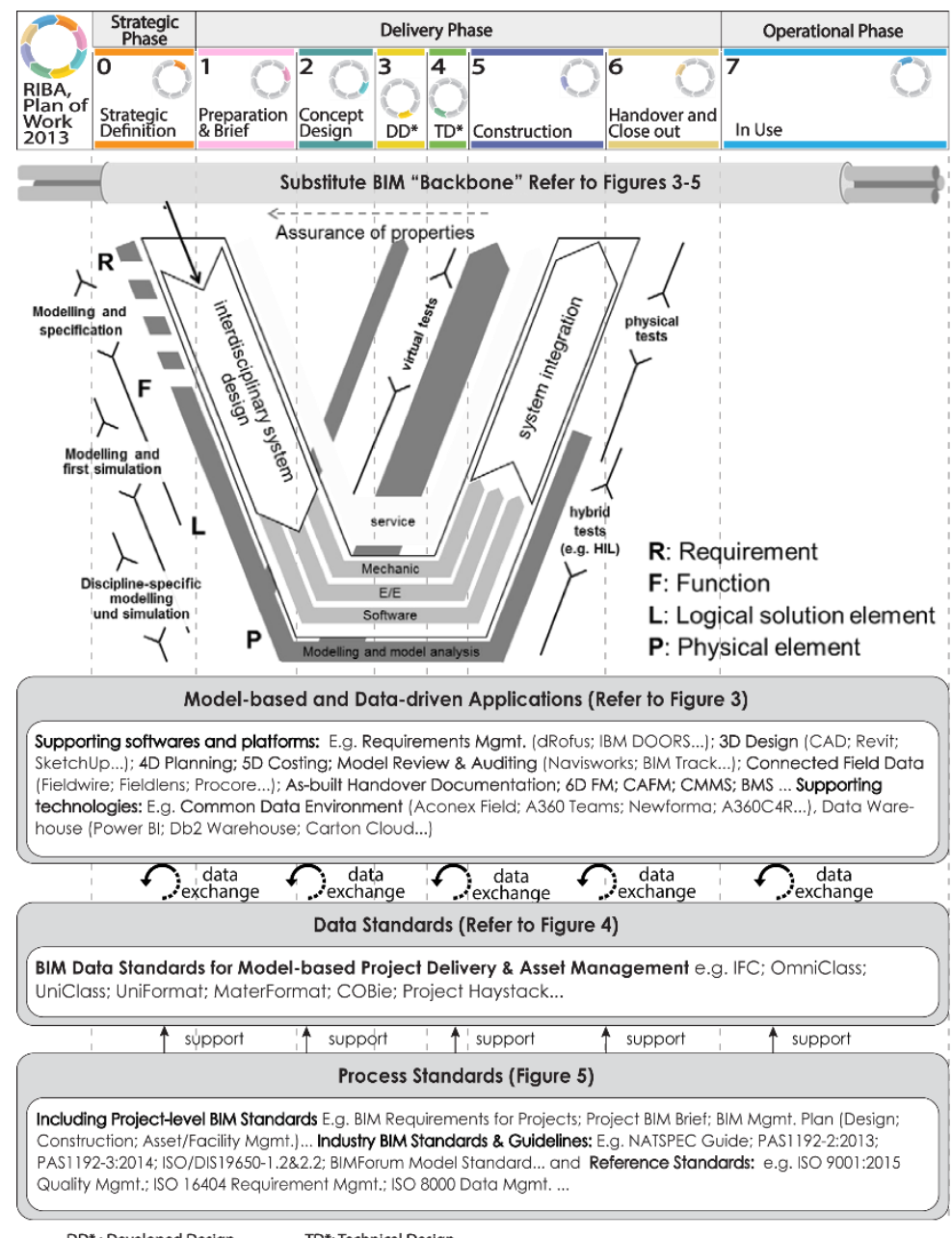

DD*: Developed Design $\quad T D^{*}$ : Technical Design

Fig. 2. Through-life information management in Complex Construction 
The framework consists of five layers: (i) Construction Asset Lifecycle Phases according to RIBA [33], (ii) MBSE PLM aligned V-model, (iii) Model-based applications (iv) Data standards, and (v) Process standards. In this framework, the RIBA's project lifecycle stages are adopted [33]. There are eight phases in total: strategic definition, preparation and brief, concept design, development design (same as schematic design), technical design (also called detail design), construction, handover and close out, and in use. The following sub-sections discuss layers (iii) to (iv).

\subsection{Model-based and Data-Driven Applications}

Model-based and data-driven applications can be broadly divided into two areas: supporting software/ platforms and supporting technologies (as shown in Fig. 3). Typical software adopted in different phases were listed according to their corresponding function. Some applications span phases, e.g. requirements management; 3D design, 4D planning, and 5D costing will have different applications according to the minimum modelling requirements specified at each phase. Applications may also occur across multiple functions based on the multifunctional modules supported.

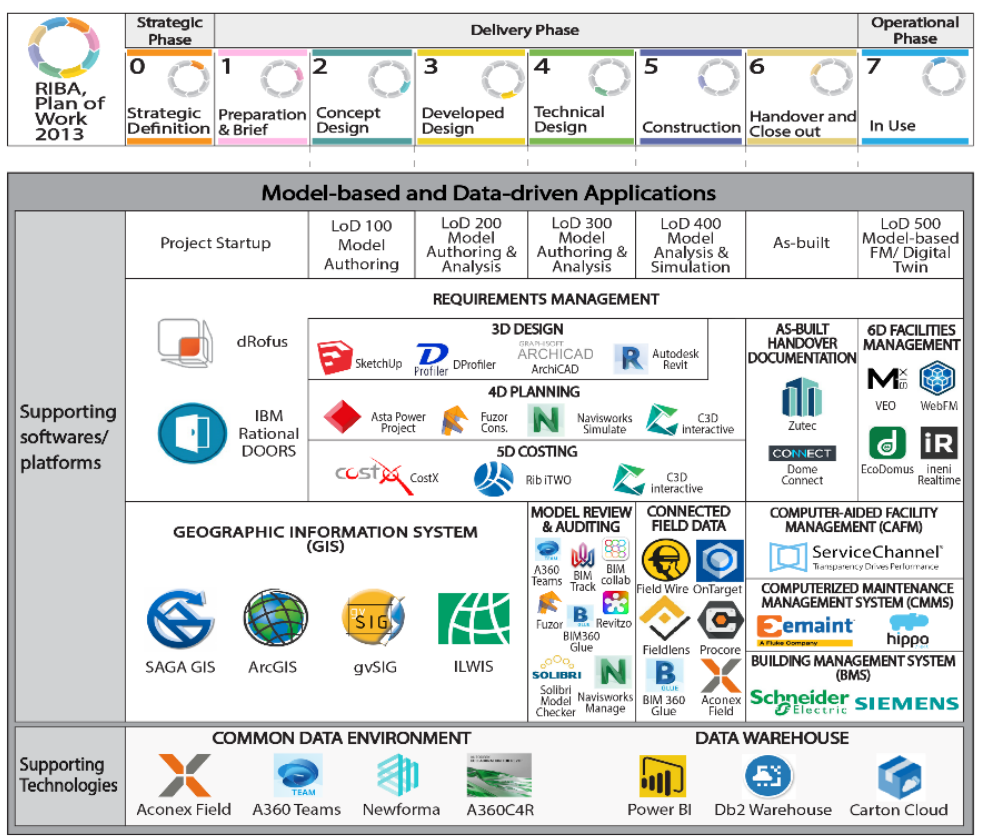

Fig. 3. Model-based and Data-Driven Applications

The use of requirements management workflows and technologies are not wide-spread in the construction industry and appear to be somewhat more common in the civil engineering and infrastructure sectors. Within these sectors, the use of requirements management tools such as IBM Rational DOORS is increasing. In the health infrastructure sector, case studies documenting BIM applications also report limited use of planning and data management tools such as dRofus, which offer requirements management capabilities that 
utilize a space-based approach to requirements management [34]. However, interactions between multiple dependent requirements remain independent, and links to the model to automate traceability are seemingly uncommon according to our review of the few academic studies documenting its use. To support data integration, Common Data Environment (CDE) platforms and data warehouses are now essential to complex construction delivery. The CDE provides an environment to share geometric information as well as related information such as registers, schedules, contracts, reports and model information. The CDE therefore builds on the concept of a "federated" model by bringing everyone's information together in a virtual space. Cloud-based platforms such as Aconex, Trimble Connect, Autodesk BIM360, GroupBC, ProjectWise and a host of Autodesk Forge's applications including AEC Hub, provide different forms of CDE.

Due to the complexity of the tool ecologies utilized throughout complex construction project delivery phases, a variety of data and process standards have been developed and despite the growing maturity in collaborative modeling software and $\mathrm{CDE}$, they remain bolt-on solutions to the systems integration problem that persist due to construction's fragmented supply chain and typical design and construct (D\&C) delivery methods.

\subsection{Supporting Data Standards}

Data standards encompass a range of data exchange and data formats (as shown in Fig. 4). Data standards reviewed here are based on the classification systems proposed by Sabol [35]. Whilst standards are primarily applied during design and are directed towards supporting the onsite integration of asset equipment, recent data standards such as Project Haystack are designed for operations. One of the most commonly used data standard includes Industry Foundation Classes, or IFCs (ISO16739) were developed to support the data exchanges between different software. Uniclass is the main classification systems in the UK while the UniFormat and MasterFormat standards are well known and widely used in the North American construction context, the successor classification system, OmniClass (also known as ISO 12006-2) is also utilized worldwide [25]. COBie ${ }^{1}$ was first proposed by the US Army Corp of Engineers in 2007 [36] and was adopted as a British Standard in 2014 [37]. More recent classification systems are aimed at the O\&M phases are gaining traction in the industry. An example is the Project Haystack, which has developed an open set of tags for naming key building automation and energy components [38].

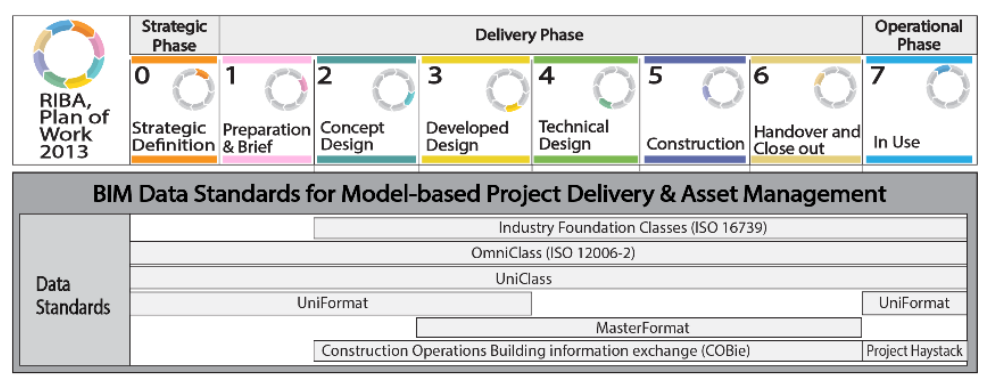

1 Construction Operation Building Information Exchange 
Fig. 4. Data Standards used in BIM-enabled Complex Construction

\subsection{Supporting Process Standards}

BIM process standards consist of the current developed project-level BIM standards informed by industry BIM standards and guidelines as well as its reference industry standards (as shown in Fig. 5). The project-level BIM standards include BIM requirements for projects, project BIM brief, and BIM execution plan (BEP), also known as a BIM management plan (BMP) for design, construction, and facility/ asset management purposes. These three types of documentations are informed by relevant industry standards and guidelines. For example, in the UK, the British Standard Institute published the PAS $^{2}$ 1192-2: 2013 and later PAS 1192-3: 2014 focusing on information management process to support BIM Level 2 in the capital/ delivery phase of projects, and operational phase $[39,40]$. Both Standards introduce new concepts and system-level processes to BIM implementation. In the US there are Level of Development specifications while in Australia there are National BIM Guide and BEP template. Internationally, the ISO/DIS 19650-1.2 and 2.2 are aimed to support the information management during the life cycle of built assets when using BIM [41]. Industry BIM standards are supported or informed by several reference standards to support quality management (ISO 9001:2005), asset management (ISO 55000 series), data management (ISO 8000), requirement management (ISO 16404).

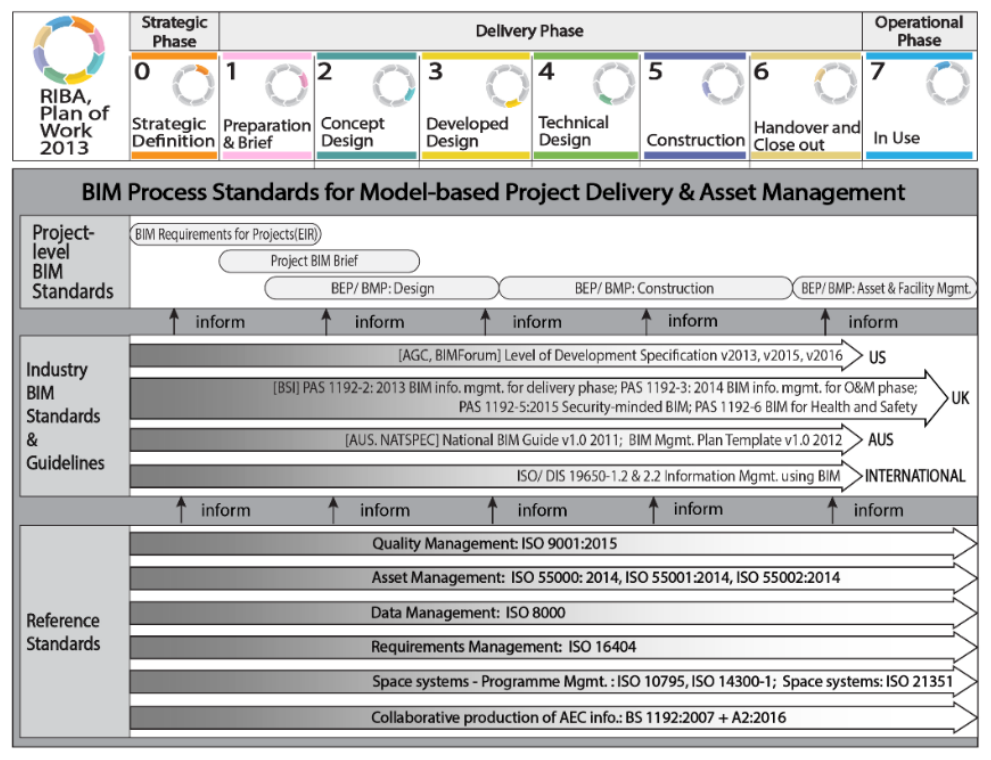

Fig. 5. Process Standards used in BIM-enabled Complex Construction

2 Publicly Available Specification 


\section{Conclusion and Ongoing Research}

The development of BIM as an enterprise strategy that can integrate and streamline the flow of information about product and product-related processes through-life (supporting the right information, in the right context, at the right time) is a central motivator of this research project. This paper has therefore sought to investigate SE and MBSE and enumerate their relevance in support of a BIM-enabled approach, where through-life information management continues to prove to be challenging to AEC project teams [7]. The $\mathrm{V}$-Model is a widely accepted approach to the development process in complex discrete manufacturing. By supporting requirements management, continuous $\mathrm{V} \& \mathrm{~V}$ and configurations management of product and product-related information throughout development processes, this simple structuring of systems decomposition and integration demonstrates a relevant method and technology infrastructure that can benefit construction and FM industries. Erasmus' PLM V-model [32] demonstrates how the backbone infrastructure and enterprise level approach of PLM is required to achieve model-based systems integration and its inherent relevance to $\mathrm{V} \& \mathrm{~V}$ and configurations management throughout the development process. These capabilities, whilst developed in a complex discrete manufacturing context, have relevance in the model-based development and O\&M of complex built assets; that is, where 3D deliverables are mandated by clients contractually.

Throughout the life of a built asset, different requirements come into and out of specification and management processes. To leverage the value of BIM in construction, system-based information management processes across all phase of the lifecycle must not only account for a variety of model-based applications and data standards, but also implement industry (e.g. ISO/DIS 19650) and project (e.g., Design BMP/ BEP) standards without structured workflows. The need to include structured requirements management and $\mathrm{V} \& \mathrm{~V}$ processes, supporting model-based data structures and backbone technology infrastructure is key to supporting through-life information management in complex construction.

The overall aim of this research is to develop new approaches to the through-life management of model-based information in the context of complex construction. Ongoing research is therefore focused on documenting industry practice in case studies that utilize $\mathrm{SE} / \mathrm{MBSE}$ methods, including PLM technology infrastructures and supporting V\&V and configurations management activities and toolsets. Case studies are targeting both complex discrete manufacturing where these approaches are more readily observable, but also notable cases in civil infrastructure and complex hospital projects. The goal is to minimize the need for manual, time-consuming, error prone, point-mapping between information systems across the lifecycle phases of complex built assets.

\section{References}

1. Hoeber H, Alsem D (2016) Life-cycle information management using open-standard BIM. Eng Constr Archit Manag 23:696-708. doi: 10.1108/ECAM-01-2016-0023

2. Green SD, Newcombe R, Fernie S, Weller S (2004) Learning across business sectors: Knowledge sharing between aerospace and construction. The University of Reading, Reading

3. Whyte JK, Hartmann T (2017) How digitizing building information transforms the built environment. Build Res Inf 45:591-595. doi: 10.1080/09613218.2017.1324726 
4. Eastman C, Eastman CM, Teicholz P, Sacks R, Liston K (2011) BIM handbook: A guide to building information modeling for owners, managers, designers, engineers and contractors. John Wiley \& Sons

5. Barlish K, Sullivan K (2012) How to measure the benefits of BIM - A case study approach. Autom Constr 24:149-159. doi: 10.1016/j.autcon.2012.02.008

6. Love PED, Matthews J, Simpson I, Hill A, Olatunji OA (2014) A benefits realization management building information modeling framework for asset owners. Autom Constr 37:1-10. doi: 10.1016/j.autcon.2013.09.007

7. Jupp JR, Awad R (2017) BIM-FM and Information Requirements Management: Missing Links in the AEC and FM Interface. In: Product Lifecycle Management and the Industry of the Future. Springer, Cham, pp 311-323

8. Anderson A, Marsters A, Dossick CS, Neff G (2012) Construction to operations exchange: Challenges of implementing COBie and BIM in a large owner organization. pp 688-697

9. Jupp JR (2016) Cross industry learning: a comparative study of product lifecycle management and building information modelling. Int J Prod Lifecycle Manag 9:258-284

10. Boton C, Rivest L, Forgues D, Jupp JR (2016) Comparing PLM and BIM from the Product Structure Standpoint. In: Harik R, Rivest L, Bernard A, Eynard B, Bouras A (eds) Product Lifecycle Management for Digital Transformation of Industries. Springer International Publishing, Cham, pp 443-453

11. Blockley DI, Godfrey P (2000) Doing it Differently: Systems for Rethinking Construction. Thomas Telford

12. Aslaksen EW, Delamare M, Fehon K, Godau R, Knott A, Kouassi A, De Liefde J (2012) Guide for the application of systems engineering in large infrastructure projects. INCOSE Infrastruct Work Group San Diego

13. INCOSE (2006) Systems Engineering Handbook. A Guide for System Life Cycle Processes and Activities, v.3. INCOSE, Seattle, WA, USA

14. Whyte $\mathbf{J}$ (2016) The future of systems integration within civil infrastructure: A review and directions for research. INCOSE Int Symp 26:1541-1555. doi: 10.1002/j.2334-5837.2016. 00244.x

15. Sage AP, Rouse WB (2009) Handbook of systems engineering and management. John Wiley \& Sons

16. Lindkvist C, Stasis A, Whyte J (2013) Configuration Management in Complex Engineering Projects. Procedia CIRP 11:173-176. doi: 10.1016/j.procir.2013.07.046

17. Morris PW (1997) The management of projects. Thomas Telford

18. Whyte J, Stasis A, Lindkvist C (2016) Managing change in the delivery of complex projects: Configuration management, asset information and 'big data.' Int J Proj Manag 34:339-351. doi: 10.1016/j.ijproman.2015.02.006

19. Xu X, Ma L, Ding L (2014) A Framework for BIM-Enabled Life-Cycle Information Management of Construction Project. Int J Adv Robot Syst 11:126. doi: 10.5772/58445

20. Zadeh PA, Wang G, Cavka HB, Staub-French S, Pottinger R (2017) Information Quality Assessment for Facility Management. Adv Eng Inform 33:181-205. doi: 10.1016/j.aei.2017.06.003

21. Hedberg T, Feeney AB, Helu M, Camelio JA (2017) Toward a Lifecycle Information Framework and Technology in Manufacturing. J Comput Inf Sci Eng 17:021010

22. Lemberger ID, Erasmus LD (2014) Systems engineering management process maturity of South African manufacturing organisations. In: Management of Engineering \& Technology (PICMET), 2014 Portland International Conference on. IEEE, pp 2371-2380

23. Ameri F, Dutta D (2005) Product lifecycle management: closing the knowledge loops. Comput-Aided Des Appl 2:577-590

24. Jupp JR, Nepal M (2014) BIM and PLM: comparing and learning from changes to professional practice across sectors. In: IFIP International Conference on Product Lifecycle Management. Springer, pp 41-50

25. Boton C, Rivest L, Forgues D, Jupp J (2018) Comparison of Shipbuilding and Construction Industries from the Product Structure Standpoint. Int J Prod Lifecycle Manag (to appear)

26. Matar M, Osman H, Georgy M, Abou-Zeid A, El-Said M (2017) A systems engineering approach for realizing sustainability in infrastructure projects. HBRC J 13:190-201. doi: 10.1016/j.hbrcj.2015.04.005

27. de Graaf RS (Robin), Vromen RM (Rick), Boes J (Hans) (2017) Applying systems engineering in the civil engineering industry: an analysis of systems engineering projects of a Dutch water board. Civ Eng Environ Syst 34:144-161. doi: 10.1080/10286608.2017.1362399

28. INCOSE T (2007) Systems Engineering Vision 2020. INCOSE-TP-2004-004-02), http://www. incose. org/ProductsPubs/pdf/SEVision2020_20071003_v2_03.pdf

29. Eigner M, Dickopf T, Apostolov H, Schaefer P, Faißt K-G, Keßler A (2014) System lifecycle management: Initial approach for a sustainable product development process based on methods of model based systems engineering. In: IFIP International Conference on Product Lifecycle Management. Springer, Berlin, Heidelberg, pp 287-300 
30. FHWA (2007) Systems Engineering for Intelligent Transportation Systems

31. Locatelli G, Mancini M, Romano E (2014) Systems Engineering to improve the governance in complex project environments. Int J Proj Manag 32:1395-1410. doi: 10.1016/j.ijproman.2013.10.007

32. Erasmus J, Jacob M, Erasmus LD (2015) The need for PLM in South Africa

33. RIBA Project stages. In: Imp. Coll. Lond. http://www.imperial.ac.uk/admin-services/estates-projects/project-procedures/stages/. Accessed 5 Apr 2018

34. Product |dRofus. http://www.drofus.no/en/product.html. Accessed 27 Apr 2018

35. Sabol L (2008) Challenges in cost estimating with Building Information Modeling. IFMA World Workplace $1-16$

36. East WE, Brodt W (2007) BIM for construction handover. J Build Inf Model 2007:28-35

37. Pärn EA, Edwards DJ, Sing MCP (2017) The building information modelling trajectory in facilities management: A review. Autom Constr 75:45-55. doi: 10.1016/j.autcon.2016.12.003

38. Home - Project Haystack. https://project-haystack.org/. Accessed 17 Mar 2018

39. BSI (2014) PAS 1192-3: 2014 Specification for information management for the operational phase of assets using building information modelling. The British Standards Institution

40. BSI (2013) PAS 1192-2: 2013 Specification for information management for the capital/delivery phase of construction projects using building information modelling. The British Standards Institution

41. ISO (2018) ISO/DIS 19650 Organization of information about construction works - Information management using building information modelling. Draft

1. Hoeber, H., Alsem, D.: Life-cycle information management using open-standard BIM. Eng. Constr. Archit. Manag. 23, 696-708 (2016). https://doi.org/10.1108/ECAM-01-2016-0023

2. Green, S.D., Newcombe, R., Fernie, S., Weller, S.: Learning across business sectors: Knowledge sharing between aerospace and construction. The University of Reading, Reading (2004)

3. Whyte, J.K., Hartmann, T.: How digitizing building information transforms the built environment. Build. Res. Inf. 45, 591-595 (2017). https://doi.org/10.1080/09613218.2017. 1324726

4. Eastman, C., Eastman, C.M., Teicholz, P., Sacks, R., Liston, K.: BIM Handbook: A Guide to Building Information Modeling for Owners, Managers, Designers, Engineers and Contractors. Wiley, Hoboken (2011)

5. Barlish, K., Sullivan, K.: How to measure the benefits of BIM - a case study approach. Autom. Constr. 24, 149-159 (2012). https://doi.org/10.1016/j.autcon.2012.02.008

6. Love, P.E.D., Matthews, J., Simpson, I., Hill, A., Olatunji, O.A.: A benefits realization management building information modeling framework for asset owners. Autom. Constr. 7, 110 (2014). https://doi.org/10.1016/j.autcon.2013.09.007

7. Jupp, J., Awad, R.: BIM-FM and information requirements management: missing links in the AEC and FM interface. In: Ríos, J., Bernard, A., Bouras, A., Foufou, S. (eds.) PLM 2017. IAICT, vol. 517, pp. 311-323. Springer, Cham (2017). https://doi.org/10.1007/9783-319-72905-3_28

8. Anderson, A., Marsters, A., Dossick, C.S., Neff, G.: Construction to operations exchange: challenges of implementing COBie and BIM in a large owner organization, pp. 688-697 (2012)

9. Jupp, J.R.: Cross industry learning: a comparative study of product lifecycle management and building information modelling. Int. J. Prod. Lifecycle Manag. 9, 258-284 (2016)

10. Boton, C., Rivest, L., Forgues, D., Jupp, J.: Comparing PLM and BIM from the product structure standpoint. In: Harik, R., Rivest, L., Bernard, A., Eynard, B., Bouras, A. (eds.) PLM 2016. IAICT, vol. 492, pp. 443-453. Springer, Cham (2016). https://doi.org/10.1007/978-3-319-54660-5_40

11. Blockley, D.I., Godfrey, P.: Doing it Differently: Systems for Rethinking Construction. Thomas Telford, London (2000) 
12. Aslaksen, E.W., et al.: Guide for the application of systems engineering in large infrastructure projects. INCOSE Infrastructure Working Group San Diego (2012)

13. INCOSE: Systems Engineering Handbook. A Guide for System Life Cycle Processes and Activities, v.3. INCOSE, Seattle (2006)

14. Whyte, J.: The future of systems integration within civil infrastructure: a review and directions for research. INCOSE Int. Symp. Banner 26, 1541-1555 (2016). https://doi.org/10.1002/j.2334-5837.2016.00244.x

15. Sage, A.P., Rouse, W.B.: Handbook of Systems Engineering and Management. Wiley, Hoboken (2009)

16. Lindkvist, C., Stasis, A., Whyte, J.: Configuration management in complex engineering projects. Procedia CIRP 11, 173-176 (2013). https://doi.org/10.1016/j.procir.2013.07.046

17. Morris, P.W.: The Management of Projects. Thomas Telford, London (1997)

18. Whyte, J., Stasis, A., Lindkvist, C.: Managing change in the delivery of complex projects: configuration management, asset information and 'big data'. Int. J. Proj. Manag. 34, 339351 (2016). https://doi.org/10.1016/j.ijproman.2015.02.006

19. Xu, X., Ma, L., Ding, L.: A framework for BIM-enabled life-cycle information management of construction project. Int. J. Adv. Robot. Syst. 11, 126 (2014). https://doi.org/10.5772/58445

20. Zadeh, P.A., Wang, G., Cavka, H.B., Staub-French, S., Pottinger, R.: Information quality assessment for facility management. Adv. Eng. Inform. 33, 181-205 (2017). https://doi.org/10.1016/j.aei.2017.06.003

21. Hedberg, T., Feeney, A.B., Helu, M., Camelio, J.A.: Toward a lifecycle information framework and technology in manufacturing. J. Comput. Inf. Sci. Eng. 17, 021010 (2017)

22. Lemberger, I.D., Erasmus, L.D.: Systems engineering management process maturity of South African manufacturing organisations. In: Portland International Conference on Management of Engineering \& Technology (PICMET), pp. 2371-2380. IEEE (2014)

23. Ameri, F., Dutta, D.: Product lifecycle management: closing the knowledge loops. Comput. Aided Des. Appl. 2, 577-590 (2005)

24. Jupp, J.R., Nepal, M.: BIM and PLM: comparing and learning from changes to professional practice across sectors. In: Fukuda, S., Bernard, A., Gurumoorthy, B., Bouras, A. (eds.) PLM 2014. IAICT, vol. 442, pp. 41-50. Springer, Heidelberg (2014). https://doi.org/10.1007/9783-662-45937-9_5

25. Boton, C., Rivest, L., Forgues, D., Jupp, J.: Comparison of shipbuilding and construction industries from the product structure standpoint. Int. J. Prod. Lifecycle Manag. 11, 191-220 (2018). https://doi.org/10.1504/IJPLM.2018.094714

26. Matar, M., Osman, H., Georgy, M., Abou-Zeid, A., El-Said, M.: A systems engineering approach for realizing sustainability in infrastructure projects. HBRC J. 13, 190-201 (2017). https://doi.org/10.1016/j.hbrcj.2015.04.005

27. (Robin) de Graaf, R.S., (Rick) Vromen, R.M., (Hans) Boes, J.: Applying systems engineering in the civil engineering industry: an analysis of systems engineering projects of a Dutch water board. Civ. Eng. Environ. Syst. 34, 144-161 (2017). https://doi.org/10.1080/10286608.2017.1362399

28. INCOSE T: Systems Engineering Vision 2020. INCOSE-TP-2004-004-02 (2007). http://www.ccose.org/media/upload/SEVision2020_20071003_v2_03.pdf

29. Eigner, M., Dickopf, T., Apostolov, H., Schaefer, P., Faißt, K.-G., Keßler, A.: System lifecycle management: initial approach for a sustainable product development process based on methods of model based systems engineering. In: Fukuda, S., Bernard, A., Gurumoorthy, B., Bouras, A. (eds.) PLM 2014. IAICT, vol. 442, pp. 287-300. Springer, Heidelberg (2014). https://doi.org/10.1007/978-3-662-45937-9_29 
30. FHWA: Systems Engineering for Intelligent Transportation Systems (2007)

31. Locatelli, G., Mancini, M., Romano, E.: Systems engineering to improve the governance in complex project environments. Int. J. Proj. Manag. 32, 1395-1410 (2014). https://doi.org/10.1016/j.ijproman.2013.10.007

32. Erasmus, J., Jacob, M., Erasmus, L.D.: The need for PLM in South Africa (2015)

33. RIBA Project stages. Imperial College London. http://www.imperial.ac.uk/admin-services/estates-projects/project-procedures/stages/. Accessed 5 Apr 2018

34. Product|dRofus. http://www.drofus.no/en/product.html. Accessed 27 Apr 2018

35. Sabol, L.: Challenges in cost estimating with Building Information Modeling. IFMA World Workplace, pp. 1-16 (2008)

36. East, W.E., Brodt, W.: BIM for construction handover. J. Build. Inf. Model. 2007,28-35 (2007)

37. Pärn, E.A., Edwards, D.J., Sing, M.C.P.: The building information modelling trajectory in facilities management: a review. Autom. Constr. 75,45-55 (2017). https://doi.org/10.1016/j.autcon.2016.12.003

38. Home - Project Haystack. https://project-haystack.org/. Accessed 17 Mar 2018

39. BSI. PAS 1192-3:2014 Specification for information management for the operational phase of assets using building information modelling. The British Standards Institution (2014)

40. BSI. PAS 1192-2:2013 Specification for information management for the capital/delivery phase of construction projects using building information modelling. The British Standards Institution (2013)

41. ISO: ISO/DIS 19650 Organization of information about construction works - Information management using building information modelling, Draft (2018) 